\title{
BASE NACIONAL COMUM CURRICULAR: CENÁRIO DAS PESQUISAS CIENTÍFICAS SOBRE O PROCESSO DE PRODUÇÃO DA POLÍTICA
}

\author{
BASE NACIONAL COMÚN CURRICULAR: ESCENARIO DE INVESTIGACIÓN \\ CIENTÍFICA SOBRE EL PROCESO DE PRODUCCIÓN DE POLÍTICAS
}

\author{
NATIONAL COMMON CURRICULAR BASE: SCIENTIFIC RESEARCH SCENARIO \\ ON POLICY PRODUCTION PROCESS
}

Ana Elise Rodrigues BRUM ${ }^{1}$

\begin{abstract}
RESUMO: O foco desta pesquisa é o processo de implementação da Base Nacional Comum Curricular. O objetivo da pesquisa é compreender por meio das produções acadêmicocientíficas (PAC) as expectativas para implementação dessa política curricular. A problemática se concentra em identificar possibilidades e limitações sinalizadas pelas produções científicas para o processo de implementação da BNCC? Esta pesquisa permitiu entender desafios e expectativas que têm sido percebidos pelos pesquisadores nas perspectivas para a implementação. Este estudo está fundamentado numa abordagem qualitativa do tipo pesquisa bibliográfica. Como fonte de informações utilizou-se artigos publicados sobre o tema entre janeiro de 2016 e dezembro de 2018 no portal de periódicos da CAPES. Após categorização e análise textual, concluímos que o principal desafio será colocar em prática um currículo que foi elaborado alheio aos professores da educação básica. Como possibilidade foi apontada a união colaborativa entre a gestão das redes de ensino e a escola básica.
\end{abstract}

PALAVRAS-CHAVE: BNCC. Política curricular. Gestão escolar.

RESUMEN: El foco de esta investigación es el proceso de implementación de la Base Curricular Nacional Común. El objetivo de la investigación es comprender a través de las producciones académico-científicas - PAC las expectativas para la implementación de esta política curricular. ¿El problema se enfoca en identificar las posibilidades y limitaciones señaladas por las producciones científicas para el proceso de implementación del BNCC? Esta investigación nos permitió comprender los desafíos y expectativas que los investigadores han percibido en las perspectivas de implementación. Este estudio se basa en un enfoque cualitativo del tipo de investigación bibliográfica. Como fuente de información, utilizamos artículos publicados sobre el tema entre enero de 2016 y diciembre de 2018 en el portal de la revista CAPES. Después de la categorización y el análisis textual, llegamos a la conclusión de que el principal desafío será poner en práctica un plan de estudios diseñado fuera de los maestros de educación básica. Como posibilidad, se señaló la unión de colaboración entre la administración de las redes educativas y la escuela primaria.

PALABRAS CLAVE: BNCC. política curricular gestión escolar.

${ }^{1}$ Universidade Federal de Santa Maria (UFSM), Santa Maria - RS - Brasil. Mestrado Profissional em Políticas Públicas e Gestão Educacional. ORCID: https://orcid.org/0000-0002-5384-4114. E-mail: anaelisebr@gmail.com

RPGE- Revista on line de Política e Gestão Educacional, Araraquara, v. 24, n. 2, p. 404-411, maio/ago. 2020. E-ISSN:1519-9029. 
ABSTRACT: The focus of this research is the process of implementation of the National Common Curricular Base (BNCC - Portuguese initials). The objective of the research is to understand through the academic-scientific productions (ASP) the expectations for the implementation of this curricular policy. Does the problem focus on identifying possibilities and limitations signaled by scientific productions for the BNCC implementation process? This research allowed us to understand challenges and expectations that have been perceived by researchers in the perspectives for its implementation. This study is based on a qualitative approach of the bibliographic research type. As a source of information, we used articles published on the theme between January 2016 and December 2018 in the CAPES journal portal. After categorization and textual analysis, we conclude that the main challenge will be to put into practice a curriculum that was designed outside of basic education teachers. As a possibility, the collaborative union between the management of the education networks and the elementary school was pointed out.

KEYWORDS: BNCC. Curriculum policy. School management.

\section{Introdução}

A existência de uma base comum curricular no Brasil já estava prevista desde a Constituição de 1988, o Artigo 210 apontava para a necessidade de conteúdos mínimos para o ensino fundamental. Já na Lei de Diretrizes e Bases (1996), que abrange toda a educação básica brasileira tanto na esfera pública como na privada, em seu Inciso IV do Artigo $9^{\circ}$, também era prevista que era responsabilidade da união estabelecer, em colaboração com os Estados, o Distrito Federal e os Municípios, competências e diretrizes para a Educação Infantil, o Ensino Fundamental e o Ensino Médio, as quais iriam nortear os currículos e seus conteúdos mínimos, de modo a assegurar formação básica comum (BRASIL, 1996).

Seguindo esta orientação o norte das Diretrizes Curriculares traçadas pelo Conselho Nacional de Educação (CNE) na década de 1990, bem como de sua revisão nos anos 2000. Em 2010, o Conselho Nacional de Educação promulgou novas Diretrizes Curriculares Nacionais, ampliando e organizando o conceito de inclusão e valorização das diferenças, o atendimento à pluralidade e à diversidade cultural resgatando e respeitando as manifestações de cada comunidade (CNE/CEB n $\left.{ }^{\circ} 7 / 2010\right)$.

Para formular políticas curriculares de qualidade que surtam efeitos positivos na prática é essencial que os grupos que as elaboram ponderem as demandas da sociedade e do mundo e que vivemos, também é importante que tenham entendimento do que é currículo, para que ele serve e a quem ele será direcionado.

É importante salientar que a BNCC não é um currículo para as escolas, mas um documento de referência para a formulação dos currículos, devendo contribuir para o 
alinhamento de novas políticas educacionais que venham surgir futuramente. Logo, pode ser interpretada de formas distintas, pois será referência para profissionais da educação que atuam em mais de 5 mil sistemas de ensino municipais diferentes, em todo território do Brasil, que é um dos mais diversos do mundo em aspectos históricos, culturais e econômicos.

Diante da preocupação com os efeitos que a BNCC poderá surtir na educação brasileira esta pesquisa tem como foco o processo de implementação desta recente política curricular, uma normativa legal que vem com a promessa de garantir o conjunto de aprendizagens essenciais aos estudantes brasileiros, seu desenvolvimento integral por meio das dez competências gerais para a Educação Básica, no entanto assume que não será suficiente para combater a desigualdade que existe na educação, mas representa o início da mudança por influenciar, positivamente, no currículo, na formação de professores, formas de avaliação e na melhoria das estruturas físicas das escolas.

Com a realização desta pesquisa esperamos expandir nosso campo de conhecimento sobre a BNCC para então, fundamentar minha pesquisa de mestrado, a qual será investigar o processo de implementação dessa política na rede municipal de ensino de Santa Maria/RS. Além de contribuir para o campo teórico e pesquisadores da área da educação.

Para tanto, esperamos contribuir para a discussão sobre a implementação desta política, percebendo as possibilidades e as expectativas que os pesquisadores têm sobre o assunto. Nosso objetivo geral de pesquisa é compreender como as pesquisas acadêmico-científicas produzem análises acerca da BNCC, considerando processos de produção da prática (limites e possibilidades).

A problemática de pesquisa é identificar que possibilidades e limitações são sinalizadas pelas produções acadêmico-científica para o processo de implementação da BNCC?

Esta pesquisa nos permitirá entender o que tem sido percebido pelos pesquisadores nas perspectivas para a implementação desta política, considerando que ainda se encontra em fase inicial, focalizaremos nossos esforços de pesquisa nos desafios e expectativas para sua implementação. Desta forma também emitiremos nosso parecer sobre a BNCC.

Considerando a temática escolhida, define-se, de modo amplo, que analisamos os posicionamentos dos pesquisadores à luz das perspectivas sobre a implementação da Base Nacional Comum Curricular, as questões de pesquisa que nortearam este estudo foram: que possibilidades são anunciadas pelos autores na BNCC? E que limitações são identificadas para a implementação da BNCC nos PAC? 


\section{Fundamentação teórica}

A educação brasileira é composta de sistemas educacionais, os quais vêm se constituindo ao longo dos anos, de maneira que testemunhamos maior fluxo de surgimento de leis e políticas educacionais a partir dos últimos anos do século XX.

As políticas públicas se definem como um conjunto de ações e programas que são desenvolvidas pelo Estado para garantir e implantar leis que estão previstas nas normativas legais. Zambon (2015) compreende que uma "Política Pública" ultrapassa a ideia de intervenção do Estado em uma situação social considerada problemática, mas envolve, e está intimamente relacionado à ideia de poder.

Dessa forma, pode-se considerar que as Políticas Públicas são uma "forma contemporânea de exercício do poder nas sociedades democráticas, resultante de uma complexa interação entre Estado e sociedade", a partir da qual se definem as situações sociais a serem consideradas para intervenção do Estado (DIGIOVANNI, 2009 apud ZAMBON, 2015).

O processo de elaboração de uma política, no âmbito de uma sociedade democrática, deve ser pensada e articulada levando em consideração dois fatores, primeiro que política deve ser originada para resolver o problema de um grupo de pessoas e não ser mais uma demanda, segundo, a participação dos indivíduos que terão suas vidas atingidas por esta política deve ser ativa e seus posicionamentos considerados no momento em que o texto for formulado.

A respeito do processo de elaboração das políticas educacionais os autores trazem três conceitos de Elmore (1996, apud BALL; MAINARDES, 2011):

1) O conjunto de reformas deve ser precedente das políticas que já estão sendo operadas pelo sistema; 2) As reformas surgem de um nível singular do sistema educacional e incorporam uma mensagem singular sobre o que as escolas deveriam fazer de maneira diferente; 3) As reformas deveriam operar mais ou menos da mesma maneira independentemente das características de sua implementação.

Partindo da ideia de Mainardes (2006, apud BALL; BOWE, 1992, p. 49) as políticas educacionais funcionam em um ciclo, o ciclo de elaboração das políticas, o qual tem três grandes momentos, o primeiro é a 'política proposta', quando surge a demanda da política seja por um grupo social, demandas da prática, onde emergem disputas político-ideológicas entre representações, onde as políticas emergem, para impor suas intenções baseadas em ideais para, a partir disso, chegar a uma 'política de fato'.

A política de fato é o momento de elaboração do texto que dá forma à política proposta, esses dois momentos dão alicerces para colocar em prática as políticas. Já a 'política em um 
uso' refere-se aos discursos, os procedimentos realizados na prática pelos profissionais da educação, as interpretações feitas do documento que por vezes podem definir mudanças no próprio texto, a implementação de uma política faz parte do processo de elaboração. Esses contextos estão inter-relacionados, não têm uma dimensão temporal ou sequencial e não são etapas lineares (MAINARDES, 2006, p. 50).

\section{Metodologia}

Neste subtítulo são apresentados aspectos metodológicos, bem como teóricos que fundamentam a metodologia adotada. Esta pesquisa configura-se em um estudo de revisão bibliográfica, com abordagem qualitativa dos dados. Caracterizado por ser desenvolvido com base em material já elaborado, constituído principalmente de livros e artigos científicos. A principal vantagem da pesquisa bibliográfica reside no fato de permitir ao investigador a cobertura de uma gama de fenômenos muito mais ampla do que aquela que poderia pesquisar diretamente

Esse tipo de método que tem fundamento teórico, além de permitir desvendar processos sociais ainda pouco conhecidos referentes a grupos particulares, propícia à construção de novas abordagens, revisão e criação de novos conceitos e categorias durante a investigação (MINAYO, 2012).

Para coletar as informações realizou-se uma busca no portal de periódicos da CAPES. O aspecto temporal estabelecido foi entre janeiro de 2016, logo após a publicação da primeira versão da BNCC, e dezembro de 2018 pelo fato da busca ser realizada no primeiro semestre de 2019.

Após seleção dos artigos realizamos a análise temática de Minayo (2012) que consiste em pré-análise, exploração e categorização.

Por se tratar de uma pesquisa bibliográfica, a qual não envolve pesquisa diretamente com seres humanos, não há necessidade de aprovação em comitê de ética. Contudo, mantendo os respaldos éticos envolvidos em pesquisas, o estudo seguiu as recomendações da Resolução № 510, de 07 de abril de 2016, referente a ética nos estudos de ciências humanas e sociais. 


\section{Resultados e Constatações}

A categorização dos artigos se deu a partir das aproximações dos focos dos estudos, bem como o surgimento das subcategorias de aproximação. Neste item serão são apresentadas as categorias encontradas, bem como as discussões a cerca de cada uma.

O maior número de artigos se concentrou na categoria Níveis de Ensino, sendo localizados cinco artigos sobre a Educação Infantil, no quais percebemos uma série de preocupações referentes ao retrocesso que a BNCC pode representar com a política de avaliação da educação infantil, na medida em que propõe uma formação mais generalista. Já sobre o Ensino Fundamental encontramos apenas um artigo, o qual define que a linguagem técnica do documento tem sido um obstáculo, comprometendo a sua compreensão e implementação. A respeito do Ensino Médio percebeu-se certa preocupação com a ideia de que a BNCC reforça as políticas curriculares que já existiam, sendo criadas com o objetivo de implantar um ensino por competências, limitador.

Na categoria, Componentes Curriculares na BNCC, notou-se expectativas positivas no texto da política em torno dos componentes: educação física, história e língua inglesa. Devido ao fato de os conteúdos divergirem com a contemporaneidade. Nos componentes, literatura, ciências e geografia os autores apresentaram, majoritariamente, críticas negativas, denunciando a desvalorização da formação humana no currículo, priorizando o ensino voltado ao mercado de trabalho. Bem como a frágil participação de especialistas e da comunidade escolar.

Tal fenômeno foi percebido especialmente, na terceira versão da BNCC, a qual foi elaborada praticamente a portas fechadas pela equipe do governo Temer, pós-processo de impeachment, ocorrido em setembro de 2016. Este governo que, desde o início até os dias atuais, foi cercado por questionamentos sobre sua legitimidade, principalmente após a imposição e aprovação de propostas políticas de cunho neoliberal.

Constatou-se que os temas gênero, sexualidade e diversidade foram praticamente extintos da BNCC. O uso das tecnologias também emergiu nos PACs, sobre isso, existem dois pontos de vista, a preocupação da tecnologia como um recurso que pode representar o fim da hegemonia dos docentes em sala de aula e a preocupação no sentido da falta de espaço na BNCC.

Sobre a docência na BNCC, a formação dos professores surgiu como um assunto considerado pelos autores como um dos maiores desafios para a implementação da BNCC, outro desfio é o estabelecimento de uma parceria entre as secretarias de educação e as escolas 
com o objetivo de fornecerem formação para a implementação da política, considerando a fragmentação que se encontra atualmente.

\section{Considerações finais}

Ao prometer a garantia de um conjunto de aprendizagens essenciais e desenvolvimento integral aos estudantes brasileiros, por meio das dez competências gerais para a Educação Básica a BNCC prevê a equidade e qualidade da educação. Remete a padronização do ensino, método que já se mostrou ineficaz para resolver os problemas da educação brasileira. Por outro lado, o documento traz elementos que podem surtir efeitos positivos apontando caminhos para lidar com a contemporaneidade no interior da escola, por considerar a convergência de ideias, comportamentos e sentidos de diferentes indivíduos.

Conclui-se ainda, que não houve um debate plenamente participativo entre o MEC e a comunidade escolar, dessa forma deixando fragilidades que podem levar a uma interpretação equivocada pelas escolas. A principal conexão percebida foi entre a gestão e o processo de desenvolvimento curricular, assim como a discussão sobre a influência da Nova Gestão Pública (NGP) na educação brasileira, movimento baseado em critérios econômicos que vem repercutindo tanto no ensino quanto na aprendizagem.

\section{REFERÊNCIAS}

BRASIL. Lei n. 9.394, de 20 de dezembro de 1996. Estabelece as diretrizes e bases da educação nacional. Diário Oficial da União, Brasília, DF, 23. dez. 1996. Disponível em: http://www2.camara.leg.br/legin/fed/lei/1996/lei-9394-20-dezembro-1996-362578publicacaooriginal-1-pl.html. Acesso em: 17.fev.2014.

BRASIL. Ministério da Educação. Secretaria de Educação Básica. Diretrizes Curriculares Nacionais Gerais da Educação Básica. Ministério da Educação. Secretária de Educação Básica. Diretoria de Currículos e Educação Integral. Brasília: MEC, SEB, DICEI, 2013. 542p. Disponível em:

http://portal.mec.gov.br/index.php?option=com_docman\&view=download\&alias=15548-d-cn-educacao-basica-nova-pdf\&Itemid=30192. Acesso em: 6 set. 2018.

ZAMBON, Luciana B. Organização e desenvolvimento do trabalho escolar no contexto de implementação da proposta de reestruturação curricular do ensino médio da SEDUC/RS. Orientador: Eduardo Adolfo Terrazzan. 2015. 359 f. Tese (Doutorado em Educação) - Universidade Federal de Santa Maria, Santa Maria, 2015.

MAINARDES, Jefferson. Abordagem do ciclo de políticas: uma contribuição para a análise de políticas educacionais. Educação \& Sociedade, Campinas, v. 27, n. 94, p. 47-69, jan./abr. 2006. 
MINAYO, Maria C. de S. Análise qualitativa: teoria, passos e fidedignidade. Ciênc. saúde coletiva, Rio de Janeiro, v. 17, n. 3, p. 621-626, mar. 2012.

\section{Como referenciar este artigo}

BRUM, Ana Elise Rodrigues. Base Nacional Comum Curricular: cenário das pesquisas científicas sobre o processo de produção da política. Revista on line de Política e Gestão Educacional, Araraquara, v. 24, n. 2, p. 404-411, maio/ago. 2020. E-ISSN:1519-9029. DOI: https://doi.org/10.22633/rpge.v24i2.13137

Submetido em: 20/11/2019

Revisões requeridas: $18 / 12 / 2019$

Aprovado em: 25/01/2020

Publicado em: 09/04/2020 